\title{
Los acuerdos de intercooperación como mecanismo jurídico de integración de cooperativas ${ }^{1}$
}

\author{
Luis Ángel Sánchez Pachón ${ }^{2}$
}

Recibido: 14 de diciembre de 2017 / Aceptado: 12 de enero de 2018

Resumen. La dimensión de las empresas constituye una de las principales estrategias a la hora de abordar muchos de los retos a los que se enfrenta el sector cooperativo. La atomización y reducida dimensión empresarial que, particularmente, presentan las cooperativas en España, se convierte en un límite de su capacidad competitiva. Alcanzar una dimensión suficiente no es solo una tendencia o necesidad de los planes de negocio, sino que, además, se presenta como una política pública fomentada y apoyada económicamente. En los momentos actuales recobra interés el estudio por las estrategias ligadas al crecimiento empresarial de las cooperativas y, por ello, a los fenómenos de integración, colaboración o cooperación.

La legislación cooperativa enuncia distintos instrumentos normativos que pueden facilitar esos fenómenos. Nos centramos en los acuerdos de intercooperación, como mecanismos jurídicos de integración cooperativa que, aunque parca y desigualmente previstos en nuestras legislaciones, pueden constituir una oportunidad que, de alguna manera, respondan a las necesidades que demanda el sector cooperativista. Explicamos la situación en la legislación española y, en especial, la regulación de los acuerdos intercooperativos. Constatamos sus deficiencias y proponemos las reformas necesarias. Buscamos que los acuerdos intercooperativos puedan convertirse en un mecanismo atractivo para el sector cooperativista y la intercooperación, que favorezca la integración cooperativa, siempre en el marco del respeto a los valores y principios del cooperativismo.

Palabras clave: Concentración; Integración; Colaboración; Acuerdos intercooperativos; Pactos intercooperativos.

Claves Econlit: P13; K12; K39; L14; L25.

\section{[en] The agreements of intercooperation as a legal mechanism for the integration of cooperatives}

Abstract. The dimension of companies is one of the main strategies when addressing many of the challenges facing the cooperative sector. The atomization and reduced business dimension that, particularly, cooperatives in Spain present, becomes a limit of their competitive capacity. Achieving a sufficient dimension is not only a trend or necessity of the business plans but, moreover, it is presented as a public policy fostered and supported economically. At present, the study is interested

1 El presente artículo ha sido realizado en el marco del Proyecto de investigación titulado Integración cooperativa y reestructuraciones socialmente responsables. Mecanismos de creación de empleo e incremento de productividad empresarial, con referencia DER2013-48864-C2-1-P (Ministerio de Economía y Competitividad), cuyo investigador principal es el profesor Dr. D. Carlos Vargas Vasserot.

2 Universidad de Valladolid, España

Dirección de correo electrónico: pachon@eco.uva.es. 
in the strategies linked to the business growth of cooperatives and, therefore, to the phenomena of integration, collaboration or cooperation.

Cooperative legislation enunciates different normative instruments that can facilitate these phenomena. We focus on intercooperation agreements, as legal mechanisms of cooperative integration that, although sparingly and unevenly foreseen in our legislation, may constitute an opportunity that, in some way, responds to the needs demanded by the cooperative sector. We explain the situation in Spanish legislation and, especially, the regulation of inter-cooperative agreements. We verify their deficiencies and propose the necessary reforms. We seek that inter-cooperative agreements can become an attractive mechanism for the cooperative sector and inter-cooperation, which favors cooperative integration, always within the framework of respect for the values and principles of cooperativism.

Keywords: Concentration; Integration; Collaboration; Intercooperative agreements; Intercooperative pacts.

Sumario. 1. Introducción. 2. Modalidades de integración y colaboración en las cooperativas y vinculación con el principio de intercooperación. 3. Los acuerdos de intercooperación como mecanismo jurídico de integración: la situación en la legislación cooperativa española. 4. Regulación de los acuerdos de intercooperación (acuerdos intercooperativos): aspectos principales de su régimen jurídico. 5. Consideraciones finales. 6. Referencias bibliográficas.

Cómo citar: Sánchez Pachón, L.A. (2017) Los acuerdos de intercooperación como mecanismo jurídico de integración de cooperativas. REVESCO. Revista de Estudios Cooperativos, Monográfico, No 126, pp. 154-176. DOI: 10.5209/REVE.58616.

\section{Introducción}

La literatura económica, desde hace tiempo, viene constatando cómo la dimensión de la cooperativa sigue siendo una de las principales estrategias a la hora de afrontar muchos de los retos a los que se enfrenta el sector cooperativo (Meliá y Juliá, 2008). El tamaño se presenta como factor de competitividad y, por ello, la reducida dimensión empresarial, que particularmente ofrecen las cooperativas en España, se presenta como un límite de su capacidad competitiva.

Es cierto que no siempre hay una relación clara y exacta entre el tamaño y la rentabilidad (Huerta y Salas, 2014). Es cierto, también, que el fenómeno de la globalización puede generar espacios de actuación eficaz para las cooperativas que no basan su competitividad en la utilización intensiva del capital o en el desarrollo de plantas productivas con rendimientos crecientes de escala. Por otra parte, también, la descentralización productiva o el desarrollo de otros sectores, a veces, propicia nuevas oportunidades para las empresas de pequeña y mediana dimensión (Monzón, 2012). Tampoco, pueden desdeñarse los peligros que entrañan las concentraciones de las cooperativas. La búsqueda de la dimensión empresarial constituye una preocupación del sector cooperativo, que, sin embargo, ve en los procesos de concentración empresarial la forma, si no la única sí la mejor, de afrontar los retos de la globalización y, a la vez, de superar algunas de las limitaciones estructurales y económicas que tienen las sociedades cooperativas para su expansión y crecimiento sin tener que abandonar su modelo empresarial (Vargas, 2010; Vargas, Gadea y Soler, 2017). En general, los estudios nos destacan las ventajas que se derivan del mayor tamaño, del crecimiento y de la colaboración (Sánchez, 2015: 128). Ventajas que se pueden concretar en la explotación de 
economías de escala; la mejora del poder de negociación con los demás agentes económicos con los que interactúan; la mayor diversificación de productos y mercados; la disminución de los riesgos (Arcas, 2011; Campos, 2011); incluso, la mejora de la gestión y del acceso a la financiación y a las tecnologías de la información y de la comunicación (Fayos, Calderón y Mir, 2011).

No es extraño así que, en momentos de crisis como los que hemos venido padeciendo, recobre interés el estudio por las estrategias ligadas al crecimiento empresarial y, por ello, a fenómenos de integración, colaboración o cooperación. Fusiones, agrupaciones, participación en empresas, alianzas, acuerdos de cooperación, etc., son mecanismos que se han venido apuntando para la consecución de esos objetivos ${ }^{3}$.

Con todo, y aun contando en España con un entorno legal pro-cooperativas potenciando los procesos de integración, la utilización de las formas de integración o colaboración empresarial no ha sido abundante. En la no utilización de los distintos mecanismos de integración o colaboración, contemplados por la legislación cooperativa, probablemente influyan muchos factores, como pueden ser: reticencia de las entidades a integrarse, desconfianzas, falta de espíritu intercooperativo, miedo o resistencia en consejeros y dirigentes de cooperativas a perder atribuciones, falta de estímulos por parte de las administraciones públicas (García et al, 2014; Antelo, 2012). Pero quizá, también el desconocimiento, unas veces, $\mathrm{y}$, otras, la inadecuación normativa a las necesidades socioeconómicas de los operadores también haya podido influir.

Como han apuntado nuestros comentaristas de relieve (Vargas, 2010), la legislación sobre esta materia, quizá, no sea siempre adecuada, pues contiene normas que, en cierta medida, limitan las posibilidades de crecimiento y expansión en el modelo cooperativo, lo que ha provocado la búsqueda de alternativas de auténtica ingeniería societaria para eludir tales limitaciones e, incluso, la transformación de la cooperativa en otro tipo de sociedades mercantiles, más cómodas para diversificar, crecer y competir en el mercado. De ahí que no falten propuestas de un régimen legal que reconozca las posibilidades de crecimiento y de diferenciación, permitiendo flexibilidad para que las cooperativas crezcan de tamaño sin perder de vista los principios cooperativos.

Frente a los instrumentos de integración más rígidos o intensos, como puede ser la fusión, la cooperativa de segundo grado $\mathrm{u}$ otros tipos de agrupaciones cooperativas, el sector cooperativista, en particular el agroalimentario, ha reclamado fórmulas de colaboración más flexibles para redimensionar las cooperativas. Aun reconociendo los efectos -ciertamente escasos- que en el sector agroalimentario puedan atribuirse a la Ley 13/2013, de 2 de agosto, de fomento de la integración de cooperativas y de otras entidades asociativas de carácter agroalimentario, lo cierto es que los mensajes que proponen las fusiones y las absorciones entre cooperativas como herramienta básica para hacer frente a los cambios del mercado, no han calado lo suficiente, propugnándose, en el ámbito cooperativo, caminos más ágiles en la gestión, propiciando acuerdos y alianzas

\footnotetext{
Resaltan, particularmente, los estudios en el sector de las cooperativas agroalimentarias, en las que en España se ha destacado su fuerte atomización como problema principal de su pervivencia y competitividad. Pueden verse: Juliá, Meliá, García, Gallego (2010) Fayos, Calderón, Mir, (2011) y referencias que allí se indican. Campos y Chaves, 2012; Del Real, 2013; también, Juliá, García, Meliá, (2012); García, Meliá, Arcas (2014).
} 
entre cooperativas que permitan empezar a trabajar de forma coordinada y ayuden a ir fraguando una relación de confianza como paso intermedio ante posibles fusiones o integraciones (Sánchez, 2015: 130).

Todo ello obliga a cuestionarnos y repensar sobre si los instrumentos de integración o de colaboración económica de las cooperativas son los más idóneos en la situación económica actual; si precisan ser revisados, si caben otros modelos de crecimiento, o, al menos, si requieren de una mejor difusión en el sector. En las páginas que siguen, una vez contrastado el papel de la integración y colaboración como estrategias de crecimiento empresarial, nos proponemos clarificar y delimitar jurídicamente las formas de colaboración e integración presentes en la legislación cooperativa y comprobar el alcance de los acuerdos de intercooperación como instrumento de integración y cooperación, que, aunque parcamente recogidas en la legislación cooperativa, en nuestra opinión, pueden constituir una respuesta eficaz a las necesidades que demanda el sector cooperativo.

Buscamos con ello poder contribuir a las propuestas de mejora de los instrumentos jurídicos que puedan dar satisfacción a necesidades que presenta la realidad cooperativa española, en unos momentos en los que la atomización del sector cooperativo, particularmente agroalimentario, se percibe como uno de los principales problemas de competitividad, y en un entorno jurídico en el que entran en juego las iniciativas nacionales favorecedoras de la integración cooperativa; lo que hace aún más necesario clarificar las perspectivas que se ofrecen a las cooperativas. En fin, con todo ello, buscamos también, suscitar la reflexión en el sector cooperativista y avivar el debate doctrinal para las mejores propuestas de las actuaciones legislativas que correspondan.

\section{Modalidades de integración y colaboración en las cooperativas y vinculación con el principio de intercooperación}

La legislación cooperativa española alude a diversos instrumentos o modalidades de integración, concentración, cooperación o colaboración: cooperativas de segundo grado, cooperativas de ulterior grado; grupo cooperativo; agrupaciones, corporaciones cooperativas, consorcios; uniones; asociaciones, sociedades, cooperativas de integración, cooperativas especiales, cooperativas de servicios, cooperativas mixtas, acuerdos intercooperativos, fusión, fusión especial. No es fácil una sistematización de todas esas modalidades ni una definición del alcance de las mismas. En la literatura científica tampoco encontramos uniformidad al abordar el significado de los diferentes instrumentos que las legislaciones, con mucha frecuencia, solo se preocupan de enunciar.

Si tomamos como referencia la Ley de cooperativas, Ley 27/1999, de 16 de julio de cooperativas (LC), se puede ver (Paniagua, 2005) que se habla de una colaboración cooperativa, en términos amplios, que se extiende en dos ámbitos diferentes: por un lado fórmulas de integración y de colaboración empresarial: cooperativas de segundo grado; grupo cooperativo y otras formas de colaboración (arts. 77-79); por otro, las fórmulas de asociacionismo cooperativo, para la defensa y promoción de sus intereses (uniones, federaciones, confederaciones u otras formas asociativas conforme al derecho de asociación (arts. 117-120). 
En el ámbito teórico del cooperativismo se suele distinguir una integración que abarca todas las formas de asociacionismo o colaboración con otras cooperativas o terceras personas, pero siempre de carácter económico, frente a una integración, que englobaría todos los vínculos que persigan la representación colectiva de más de una cooperativa o sociedad en general, para el ejercicio de acciones o defensa de intereses que no sean del interés estrictamente económico de sus componentes (Romero 2001; Morillas y Feliú, 2002). Diferenciado, así, la integración cooperativa referida a la colaboración de una finalidad empresarial, y el asociacionismo cooperativo referido a la existencia un movimiento organizado jurídicamente -asociaciones entre cooperativas- para la defensa y promoción de sus intereses (Cano, 2015 a: 55; Vargas et al., 2017) ${ }^{4}$.

En otras ocasiones se ha podido reservar los términos integración cooperativa para aquellas formas de concentración empresarial que tienen como protagonistas principales a las sociedades cooperativas y que se caracterizan por hacer compatible un alto grado de unión económica con el mantenimiento de la autonomía jurídica de quienes participan en el proyecto. Como formas o instrumentos de esa integración se señalan las cooperativas de segundo o ulterior grado y el grupo cooperativo. Sin embargo, se suele excluir por muchos autores la fusión, como forma pura de concentración, en cuanto supone la unificación no solo económica sino jurídica (Embid, 1998; Gadea, Sacristán, Vargas, 2009). Los vínculos menos intensos, normalmente de duración más reducida y que no alteren la independencia económica de las entidades partícipes, se sistematizan como una especie de sub-formas de integración, que se califican de colaboración económica o intercooperación económica. Y se reserva la intercooperación representativa para los supuestos de asociacionismo cooperativo que canalizan la defensa y representación de los intereses generales de las cooperativas y del cooperativismo (Alfonso, 2006).

Si dejamos al margen la vertiente más política de integración, que permite canalizar los supuestos de representación y defensa los intereses del cooperativismo a través de la acción colectiva (Cano, 2015 b: 31), y nos centramos en la integración cooperativa económica, observamos cómo en la literatura cooperativa parece consolidarse la diferenciación entre fórmulas con y sin vinculación patrimonial. Así, en las fórmulas con vinculación patrimonial, en las que el nexo común a todas ellas está en que las entidades participantes unen, no solo sus negocios, sino también sus balances $\mathrm{y}$, por tanto, sus patrimonios confundiéndose en una sola unidad, se incluye la fusión y la escisión en sus distintas modalidades 5 . Dentro de las fórmulas sin vinculación empresarial se

4 Vargas et al. (2017: 210), señalan que la fenomenología que cabe en el concepto amplio de integración empresarial, y que responde a la faceta puramente económica del principio cooperativo de intercooperación, es muy variada, y que la otra vertiente de ese principio se encuentra en el asociacionismo cooperativo (intercooperación representativa), orientado a la defensa y promoción política y social del cooperativismo como forma alternativa de empresa, y que se traduce en la existencia de uniones, asociaciones, federaciones y confederaciones de cooperativas. Señalando, al respecto, diversos ejemplos.

5 Del Real (2013: 327) menciona las siguientes posibilidades de integración con vinculación empresarial: fusión por creación de una nueva cooperativa; fusión por absorción; fusiones especiales entre cooperativas y otros tipos societarios, y transformación de una cooperativa de segundo o ulterior grado en una única cooperativa de primer grado. Fórmula ésta -se dice-que tiene evidentes matices similares a la fusión por absorción. Ejemplos lo constituyen el Consorcio de Promoción del Ovino, en Castilla y León, que, funcionando como cooperativa de segundo grado, pasa a ser en 2016 una cooperativa de primer grado y, recientemente, en Galicia, Aira, en la 
incluyen las cooperativas de segundo -o ulterior- grado, los grupos cooperativos ${ }^{6}$, las cooperativas de servicios $^{7}$ y otras formas de colaboración ${ }^{8}$. Las fórmulas sin vinculación patrimonial tendrán en común que parten de la existencia de empresas cooperativas independientes que desean mantener la personalidad jurídica pero que quieren iniciar un proyecto en común, para lo cual crean otras sociedades o elaboran un marco colaborativo para la puesta en común de ciertos intereses empresariales (Cano, 2015 a; Del Real, 2013: 327) ${ }^{9}$.

Se puede diferenciar, incluso, un tercer gran grupo de procesos de integración: procesos de integración anticipada, en los que, partiendo de la existencia de diversos negocios a desarrollar, que cada uno de los cuales, individualmente considerado, podría dar lugar a cooperativas independientes, se forma una integración ex ante por medio de una sola cooperativa; evitándose, de esta manera, la multiplicación y dispersión de cooperativas. Se mencionan en este grupo a las cooperativas integrales y a las secciones dentro de una misma cooperativa o, incluso, a las cooperativas integrales con secciones (Del Real 2013: 328) ${ }^{10}$. La doctrina destaca, también, que las secciones cooperativas constituyen un peculiar instituto cooperativo con el que se puede compensar la dificultad que tienen las cooperativas para contar con filiales (Vargas et al, 2017: 213). Las secciones desarrollan dentro del objeto social de la cooperativa actividades económico-

que las cooperativas socios de Aira parece que acordaron, en junio pasado, promover su fusión en una única cooperativa de primer grado, que mantendrá el nombre de Aira, http://www.agronegocios.es/\%EF\%BB\%BF\%EF\%BB\%BF-varias-cooperativas-gallegas-plantean-fusionarsecrear-aira-nueva-cooperativa-primer-grado/. y https:/www.lavozdegalicia.es/noticia/lemos/2017/07/01/nacecooperativa-aira-2800-socios-220-trabajadores/0003_201707M1C1992.htm.

6 Podría también incluirse aquí la Corporación cooperativa, forma, no obstante excepcional, que se contempla en la Ley de Cooperativas de Castilla y León (art. 127), aunque, en la práctica, no ha habido ninguna constitución. Se recoge, asimismo, en la Ley de Cooperativas de Euskadi; en ésta última, para dar reconocimiento al mayor grupo empresarial del País Vasco y al mayor grupo cooperativo del mundo: Mondragón Corporación Cooperativa (Sánchez, 2015: 148).

7 La organización instrumental que ofrece $\mathrm{s}$ la cooperativa de servicios, nos puede ofrecer, también, buenos ejemplos de intercooperación (Vañó, 2011).

8 Como fórmulas sin vinculación patrimonial, pudiendo tener diferentes grados de integración funcional, competencial o dependencia jerárquica entre las entidades participantes, Del Real (2013: 327) destaca: las cooperativas de segundo grado; los acuerdos intercooperativos; los grupos cooperativos; las sociedades participadas por cooperativas; las uniones temporales de empresa; las agrupaciones de interés económico, y los acuerdos, convenios, agrupaciones de productores y cualquier otra fórmula de colaboración sin forma jurídica específica. Por su parte, Cano (2015 a: 71), menciona, dentro de las otras fórmulas de colaboración económica, que suponen una vinculación menor (apunta la autora, sin embargo, que están limitadas por el Derecho de la competencia), la constitución de sociedades, agrupaciones, consorcios, y uniones entre sí, o con otras personas físicas o jurídicas, públicas o privadas, así como a la formalización de convenios o acuerdos, para el mejor cumplimiento de su objeto social y para la defensa de sus intereses. A ellos se añade la posibilidad, recogida en algunas leyes autonómicas, de que las sociedades cooperativas puedan poseer participaciones en las entidades mencionadas anteriormente.

9 La Sociedad Cooperativa Europea se podría utilizar tanto como fórmula de concentración con vinculación patrimonial como sin vinculación patrimonial (Cano, 205 a: 56). Fórmula, en cualquier caso, de escasísimo éxito en la práctica.

10 En las cooperativas integrales (p .e., 105 de la Ley de Cooperativas) la actividad cooperativizada es doble o plural, cumpliendo las finalidades propias de diferentes clases de cooperativas en una misma sociedad. Así se posibilita que en una única cooperativa puedan convivir diferentes actividades cooperativizadas que, de otro modo, debería dar lugar a la creación de varias cooperativas independientes.

Por lo que respecta a las Secciones, éstas permiten la integración, en una única cooperativa, de distintas actividades específicas propias del objeto social de una misma clase de cooperativa. Como el autor indica, la práctica ha sido frecuente en las actividades agrarias. 
sociales y tienen autonomía de gestión, patrimonio separado y cuentas de explotación diferenciada, como si de unidades de negocio distinto se tratase ${ }^{11}$.

Toda esa amalgama de formas de colaboración, cooperación, concentración, en nuestra opinión, puede englobarse, de alguna manera, en el concepto de integración que se emplea en el ámbito cooperativo. Aquí tiene un significado propio y diferente al que se utiliza en otros ámbitos como en el Derecho societario o en el Derecho de la competencia (Instituto para el Derecho y la Organización Empresarial, 2003: 44; Vargas et al. 2017). Un significado que puede abarcar formas de concentración, en las que se produce un cambio sustancial en cuanto al poder de decisión económica de las entidades implicadas, como también fenómenos de cooperación o colaboración económica entre cooperativas, que no alteran la independencia económica de las sociedades que se unen. Si bien, habrá que tener presente, también, que en esas integraciones, o colaboraciones, pueden distinguirse grados o escalones, que son los que nos permitirán analizar la vinculación y justificación de esa integración o acuerdos de colaboración siempre que las entidades implicadas sean cooperativas - con el sexto principio cooperativo de la Alianza Cooperativa Internacional de la intercooperación ${ }^{12}$.

Ese principio de cooperación entre cooperativas, o de intercooperación, que es un principio clásico, aunque, formalmente, se incorporara al listado de la ACI en la Declaración de Viena de 1966 (Cano, 2015 b) puede convertirse, así, en el elemento que vertebra y justifica los procesos de integración cooperativa. No puede dejar de ser significativo que el principio de la intercooperación -como se ha dicho- nazca, en gran medida, por la preocupación por el progresivo crecimiento de la dimensión de las empresas con las que las cooperativas competían y, a la vez, como respuesta a la búsqueda de las ventajas que las relaciones entre la producción y el consumo podían aportar. Ciertamente, la aplicación del principio en la marcha de la integración del cooperativismo haya sido lenta -desde luego mucho más lenta si la comparamos con la de los otros sectores guiados por las condiciones del mercado- pero ello no puede mermar su relevancia. Los principios cooperativos forman parte del derecho positivo, toda vez que son incorporados por las leyes de cooperativas. Por ello, la llamada que se hace en las leyes a esos principios no es una simple declaración de intenciones sin concreción normativa real. Nuestra doctrina y jurisprudencia ha podido defender, incluso, su carácter de auténticas normas jurídicas, directamente aplicables y a las que se someten los estatutos y los acuerdos sociales (Alfonso, 2015: 60 y referencias que la autora ahí indica).

La relevancia del principio de intercooperación supone, en nuestra opinión, que todos los supuestos que caen bajo la nomenclatura de la integración cooperativa,

11 Sin embargo -también se añade- no se puede equipar la autonomía patrimonial de las sociedades filiales respecto a su matriz con la de las secciones respecto a la sociedad cooperativa en la que se integran. Entre las sociedades filiales y entre éstas y la matriz, salvo casos excepcionales, no opera una responsabilidad conjunta o solidaria del grupo frente a terceros. En cambio, en la cooperativas con secciones, aunque del cumplimiento de las obligaciones de la actividad de la sección responde, en primer lugar, las aportaciones hechas o prometidas por los socios integrados en la misma y, en su caso, el patrimonio afecto a las resultas de las operaciones, al final, en caso de que sean insuficientes, opera la responsabilidad universal de la cooperativa, con todo su patrimonio (Vargas et al. 2017: 214).

12 El Sexto Principio de la Alianza Cooperativa Internacional, enunciado como «cooperación entre cooperativas» y normalmente conocido como de intercooperación, establece que «Las cooperativas sirven a sus socios lo más eficazmente posible y fortalecen el movimiento cooperativo trabajando conjuntamente mediante estructuras locales, nacionales, regionales e internacionales». 
deben ser tratados y resueltos como supuestos de concentración económica y no como una práctica que queda sujeta a la fiscalización legal que para las prácticas colusorias establece el Derecho de la competencia. Y ello, porque el concepto de concentración, que resulta de las disposiciones y de la práctica institucional europea, es un concepto económico -más que jurídico-formal- y extremadamente lato, que comporta distintos niveles de integración, y que pretende abarcar todas las operaciones de vinculación entre empresas con efectos similares en la estructura competencial de los mercados (Herrero, 2005). Si ello es así, y si en la valoración o análisis de los elementos para la determinación de la aplicación del Derecho antitrust (sujetos, estructura, funcionamiento del mercado, exenciones o inaplicaciones previstas en términos generales por las leyes de defensa de la competencia), el intérprete no puede dejar de tomar en consideración las especialidades de las entidades cooperativas y el valor de la intercooperación, quizá se pueda concluir que los fenómenos de integración cooperativa quedan al margen de la fiscalización legal que, para las prácticas colusorias, establece el Derecho de la competencia, sometiéndose, pues, únicamente, y cuando proceda, a los controles previstos para las concentraciones económicas.

Ahora bien -como también se ha dicho- el principio de la intercooperación no puede interpretarse de forma aislada, sino que debe tenerse en cuenta el límite que constituye el principio de autonomía e independencia - y de gestión democrática, añadimos nosotros- de las cooperativas y su vinculación con los valores cooperativos de autoayuda y de solidaridad (Cano, 2015 b. 325). Un valor, el de la solidaridad, que presenta dos vertientes: interna (entre los socios) y externa (que se extiende puertas afuera con otras entidades con las que comparten fines $u$ objetivos), y al que se podrían añadir el resto de los valores que preservan la identidad cooperativa: autorresponsabilidad, democracia, igualdad, equidad, honestidad, transparencia, responsabilidad y vocación social. Principios y valores cooperativos que, como se ha dicho, se erigen en criterios informadores, no solo de la actuación de los legisladores en materia de cooperativas, sino también de la autonomía de la voluntad de los particulares en orden a establecer nuevos pactos no previstos por la Ley (Alfonso, 2015: 58-59).

\section{Los acuerdos de intercooperación como mecanismo jurídico de integración: la situación en la legislación cooperativa española}

En el ámbito cooperativo es frecuente contemplar los acuerdos de intercooperación en términos genéricos, de tal manera que permiten su articulación en las distintas formas jurídicas que recoge la legislación. El artículo 79 de la Ley de cooperativas, que es seguido por las leyes autonómicas con dicciones muy similares, da pie para ello, toda vez que, como formas de colaboración, incluye la posibilidad para las cooperativas de constituir sociedades, agrupaciones, consorcios y uniones, entre sí, o con otras personas físicas o jurídicas, públicas o privadas, y formalizar convenios o acuerdos, para el mejor cumplimiento de su objeto social y para la defensa de sus intereses (art. 79.1). Pero, además, ese mismo artículo 79, en sus números 2 y 3 , contempla la posibilidad de fusiones, cooperativas de segundo grado, uniones temporales (art. 79.2), al lado de los acuerdos intercooperativos (art. 79.3). 
También en las sistematizaciones doctrinales, con frecuencia, esas formas de intercooperación se tratan conjuntamente (Argudo, 2007; Paniagua, 2005: Morillas y Feliú, 2002; Romero, 2001) ${ }^{13}$.

Ciertamente todas esas operaciones tienen una base contractual o convencional $\mathrm{y}$, en ese sentido, no pierden el carácter de acuerdo de intercooperación que, incluso, pueden ser utilizadas como instrumentos de integración (Paniagua, 2005; Cuenca, 2000; Embid, 1998), sin embargo, también nuestra legislación cooperativa suele tipificar unos acuerdos de intercooperación o intercooperativos (como los que se prevén en el número 3 del artículo 79 de la Ley estatal) -acuerdos intercooperativos en sentido propio, o en sentido estricto, podríamos decir- cuyo significado y aspectos principales conviene resaltar en la búsqueda de su mejor interpretación y utilización y, en su caso, de la implementación o desarrollo legislativo necesario.

\subsection{Acuerdos de intercooperación: Modalidades}

Como hemos anticipado, el artículo 79.1 contempla como modalidades de colaboración las siguientes: sociedades, agrupaciones, consorcios y uniones, además de convenios o acuerdos, para el mejor cumplimiento de su objeto social y para la defensa de sus intereses. Con similares nomenclaturas se hace referencia a estas formas de colaboración en las leyes de cooperativas autonómicas. Algunas amplían los supuestos: asociaciones; participaciones en entidades; agrupaciones... las legislaciones no ofrecen una fórmula jurídica concreta ni una regulación específica. Ello, sin duda, da autonomía y flexibilidad de actuación al cooperativismo (recordemos, a este respecto, que el sector cooperativista, particularmente en los últimos tiempos, reclama flexibilidad en los procesos de integración), que puede encontrar aquí diversos instrumentos de integración cooperativa, en los que, no obstante y en todo caso, como antes señalábamos, los principios y valores se erigen en criterios informadores y límite de la autonomía de la voluntad de los particulares en orden a establecer cualquier tipo de pacto o acuerdo.

Aunque las legislaciones únicamente se limitan a enunciar modalidades de colaboración, quizá convenga explicar, aunque sea someramente, las posibilidades que ofrecen cada una de ellas. Máxime cuando el sector cooperativista parece mostrar cada vez mayor interés en esos instrumentos como mecanismos de integración cooperativa ${ }^{14}$.

13 Meliá y Juliá (2008), al explicar las posibilidades y ventajas de lo que se conoce como redes de empresas (definidas como sistema o conjunto de empresas, entre las que no existe relación de subordinación, que mantienen diversos vínculos cooperativos, por medio de los cuales son capaces de realizar acciones conjuntas coordinadas, y nacidas - se dice- de la idea de que el establecimiento de alianzas entre empresas puede reportar sinergias y relaciones de complementariedad que mejoren los resultados del conjunto) vienen a configurarse como derivación de los acuerdos de cooperación entre cooperativas que se articularían, «sobre la base de alguna de las formas jurídicas existentes en nuestra legislación, tales como las cooperativas de segundo grado, las agrupaciones de interés económico, los grupos cooperativos, las Uniones Temporales de empresas, etc., a través de convenios de colaboración, sin que sea necesario el crear una nueva organización con forma jurídica, pudiendo constituir en una red distintas modalidades de cooperación».

14 La conclusiones del estudio de la doctora Ma Pía Carnicer Andrés, en su tesis sobre los nuevos modelos organizativos de las cooperativas agroalimentaria europeas y españolas (Valencia, 2017), reflejan que existen diversos modelos estructurales con los que las cooperativas agroalimentarias europeas instrumentalizan el 
Podemos sistematizarlos en dos grandes grupos: por un lado, la constitución de sociedades, asociaciones, consorcios y uniones de empresas y, por otro, la participación de cooperativas en sociedades.

En el primero de los casos, estaremos ante vinculaciones directas, que crean relaciones duraderas entre las cooperativas y la entidad o entidades con las que participan, y que pueden dar lugar a la posibilidad de controlar o de ejercer una influencia efectiva en la gestión de la nueva estructura. Las cooperativas, junto con otras entidades, pueden mostrarse así como promotoras del proyecto de agrupación, que puede dar lugar, incluso, a la formación de un grupo, bien de base contractual y paritaria, bien por subordinación, basada en la participación.

Se habla, en primer lugar, de la posibilidad de constituir sociedades. No se añade ningún calificativo, por lo que pueden subsumirse tanto en el marco de las sociedades civiles como en los diferentes tipos mercantiles. En este caso, la literatura científica suele destacar el papel que puede desempeñar la sociedad de responsabilidad limitada, donde el juego que se reconoce a la autonomía de la voluntad permitiría, con mayor facilidad, la integración cooperativa, aunque las experiencias extranjeras y nacionales nos muestran también la acogida de la sociedad anónima (Alfonso, 2006) ${ }^{15}$. De una u otra forma, esas combinaciones, como se ha apuntado en nuestra doctrina, plantean la necesidad de meditar sobre todo esto y preguntarnos por qué muchas cooperativas han acudido a verdaderas operaciones de ingeniería societaria para sortear los obstáculos que para el crecimiento y expansión encontraban en las fórmulas tradicionales de integración previstas en la legislación cooperativa (Vargas, 2010:169-170; Vargas et al. 2017: 215).

Tampoco se pueden descartar otras fórmulas, como la Agrupación de Interés Económico, cuya finalidad es el desarrollo o mejorar los resultados de la actividad de sus socios y, su objeto, el ejercicio de una actividad económica auxiliar; o como la Unión Temporal de Empresas ${ }^{16}$. Incluso, se admite también en la doctrina la contratación por las cooperativas de cuentas en participación (arts. 239 y ss. del Código de Comercio), cuya naturaleza societaria, aunque no ha dejado de estar discutida, hoy parece más segura, si bien, su régimen, en nuestra opinión, tampoco resulta muy adecuado para una integración comprometida; más bien cabría hablar, en este caso, de una mera participación.

Se alude también a la posibilidad de constituir asociaciones. La mención no aparece en todas las legislaciones, aunque sí lo reconocen las leyes de cooperativas

crecimiento, que van desde las estructuras de propiedad tradicional hasta modelos en los que la forma cooperativa incorpora atributos más característicos de las sociedades de corte capitalista, pudiendo llegar a crear sociedades de capital que actúan como sociedad holding bajo control de la cooperativa, en mayor o menor medida. Existiendo, también, fórmulas intermedias como son las estructuras de propiedad híbrida, en las que -a pesar de que se ha dado cabida a inversores externos e, incluso, en ocasiones se ha dado un cambio de forma jurídica-, la mayoría de la propiedad y control sigue en manos de los socios.

15 Algunos autores (Juliá et al., 2012), a partir de las experiencias extranjeras que analizan, constatan que, pese a que la creación de sociedades anónimas es un modelo que ha tenido buena acogida, no está exento de dificultades o riesgos: conflictos de interés entre distintos tipos de socios de las cooperativas; pérdida de control, cuando las necesidades de capital llevan a ampliaciones de capital. Puede verse, también, Gadea et al. (2009).

16 Convendrá advertir, no obstante, que la consideración como resultados cooperativos de las operaciones solo será a efectos de realizar las operaciones establecidas a los fondos sociales, pues, a efectos fiscales, se consideran rendimientos extracooperativos (Cano, 2015: 72). 
de la Comunidad Valenciana, Aragón, Andalucía, Castilla y León, La Rioja, Galicia y Euskadi. En nuestra opinión, sin embargo, la referencia a la constitución de asociaciones con fines de colaboración económica no resulta muy adecuada y confunde y complica - más que facilita - la pretensión de un reconocimiento de la asociación como instrumento de colaboración o integración, que excede a la mera organización representativa generalmente atribuida al asociacionismo cooperativo $^{17}$.

La Ley orgánica 1/2002, de 22 de marzo, reguladora del Derecho de asociación, desarrolla ese derecho reconocido en el artículo 22 de la CE. Con arreglo a lo que de esa Ley orgánica se deriva habría que decir que en sí mismas, en principio, las asociaciones comúnmente no son empresas o, si se quiere, no tienen como objetivo - en definitiva como causa del negocio jurídico que las sustenta y da origen - la realización de actividades económicas; estas actividades solo pueden ser un medio para la realización del fin fundacional o constitutivo (general o particular pero, en cualquier caso, no lucrativo). Ciertamente, aunque las asociaciones no pueden tener ánimo de lucro, sí pueden realizar actividades económicas (artículo 13 de la referida Ley orgánica) de modo principal y aun exclusivo, pero siempre que se realicen con carácter instrumental respecto de los fines de la asociación; por lo que cabe concluir que esos fines condicionarán toda la actuación. Si esa instrumentalidad no existiera y los resultados de la actividad empresarial no se dedicaran exclusivamente al cumplimiento de los fines de la asociación - como requiere el mencionado artículo 13- verdaderamente no estaríamos ante una asociación sino ante una sociedad, con independencia de la configuración formal que se haya querido otorgar a esa corporación.

Referencia especial merece la alusión a los consorcios. Aunque también se mencionan expresamente en la mayoría de las leyes de cooperativas de nuestro país, no dejan de ser una figura imprecisa que no evoca una identificación tipológica concreta (Argudo, 2007). En cualquier caso, la alusión a los consorcios que se hace en las leyes cooperativas no parece que tenga nada que ver con los consorcios que se posibilitan en el ámbito del Derecho administrativo (artículo 84.1 c) y 118 y ss., de la Ley 40/2015, de 1 de octubre, de Régimen Jurídico del Sector Público), que forman parte del sector público institucional del Estado, aunque puedan participar de su naturaleza. Ésta, como han señalado algunos comentaristas, más bien alude a una fórmula societaria de impronta mutualista, que se configura propiamente con la finalidad de potenciar la actividad de sus miembros, generalmente empresarios (Embid, 1998). En el ámbito cooperativo la génesis de los consorcios se vincula al establecimiento de una cooperación entre empresas que, además de no comprometer patrimonialmente, es muy flexible y permite abordar proyectos imposibles o difíciles de realizar de manera individual (Alfonso, 2006).

17 No obstante, la fórmula no es extraña, y puede convertirse en un instrumento organizativo e impulsor de una mejor integración empresarial. Al respecto puede verse el ejemplo de Espazccop. Creada a fínales de 2016. como entidad multisectorial de carácter empresarial, configurada como asociación sin ánimo de lucro, de ámbito gallego, integrada por cooperativas de distintas clases, inspirada en los principios cooperativos y sus valores y que tiene como objetivo, agrupar, representar, impulsar, fomentar la intercooperación y defender los intereses de sus cooperativas socias y de las personas que las constituyen, así como la divulgación, fomento y consolidación del cooperativismo, como herramienta de desarrollo socioeconómico, en el marco de la economía social y solidaria. http://espazo.coop/es/la-union/qui\%C3\%A9nes-somos/. 
En fin, la participación de las cooperativas en sociedades, como otro sistema para la agrupación empresarial, no está recogida expresamente en la Ley de cooperativas, pero sí en algunas de las leyes autonómicas, aunque no de la misma manera. En general, con esta previsión legislativa se está pensando, más que en colaboración, en posibilitar las inversiones de cartera que buscan primordial o únicamente la rentabilidad del capital invertido (Sánchez, 2015).

Uno de los peligros de la toma de participaciones de la sociedad cooperativa en otras entidades es que la cooperativa deje de desarrollar directamente la actividad propia de su objeto social, convirtiéndose en una mera sociedad holding, cuando las participaciones son mayoritarias o de control, o en una mera sociedad de cartera, en otros casos. Peligro que puede englobarse en el fenómeno que conocemos como de desmutualización y que se acrecienta en los momentos actuales. Lo intentan evitar - aunque tímidamente y genéricamente- las legislaciones, señalando que la finalidad de tales participaciones ha de ser el mejor cumplimiento, desarrollo o garantía de su fin social.

De una u otra manera la realidad económica nos viene mostrando cómo en los últimos años - especialmente en el sector agrícola y ganadero y/o alimentarioasistimos, en buena parte de la geografía española, a la creación de filiales por parte de las cooperativas, como una forma, también, de ganar segmentos de mercado, de llevar a cabo actuaciones conjuntas para reducir costes, de crear centrales de compra para comprar más barato y dar el mismo servicio. Asistimos, asimismo, a la participación de sociedades cooperativas en otras entidades nacionales e internacionales - con vistas a la creación de redes comerciales que acortan los canales de comercialización y permiten mayor presencia en los diferentes mercados (Alfonso, 2006; Carnicer, 2017).

\subsection{Acuerdos de intercooperación en sentido estricto: acuerdos intercooperativos}

Como antes anticipábamos, el artículo 79.3 de la ley estatal de cooperativas contempla, como una modalidad de colaboración económica, los acuerdos intercooperativos: «Las cooperativas podrán suscribir con otros acuerdos intercooperativos en orden al cumplimiento de sus objetos sociales. En virtud de los mismos, la cooperativa y sus socios podrán realizar operaciones de suministro, entregas de productos o servicios en la otra cooperativa firmante del acuerdo, teniendo tales hechos la misma consideración que las operaciones cooperativizadas con los propios socios.

Los resultados de estas operaciones se imputarán en su totalidad al fondo de reserva obligatorio de la cooperativa».

En términos en buena parte semejantes a los de la Ley estatal la mayor parte de nuestra la legislación autonómica prevén también los acuerdos intercooperativos como una modalidad de colaboración económica entre cooperativas. A veces se utilizan otras rúbricas y no siempre su régimen jurídico va a ser coincidente, lo que no deja de ser un obstáculo para la colaboración entre cooperativas de distintas comunidades autónomas. Hace ya unos años se denunciaba cómo el abanico de soluciones normativas divergentes ante la misma problemática que plantean los acuerdos intercooperativos «carece de toda lógica, lesiona la igualdad ante la Ley y 
la seguridad jurídica y debería ser reconducida a una regulación uniforme» ( $\mathrm{Paz}$, 2004: 137). Nuestra legislación autonómica contempla la figura de los acuerdos intercoperativos en las siguientes disposiciones y preceptos:

- Ley 12/2015, de 9 de julio, de cooperativas. Comunidad Autónoma de Cataluña. Artículo 141, bajo la denominación de "convenios intercooperativos". La nueva Ley, que deroga la Ley 18/2002, de 5 de julio, con el objetivo de simplificación y la eliminación de cargas, suprimió la obligación legal de elevar a escritura pública e inscribir los convenios intercooperativos en el Registro de Cooperativas, porque -dice la exposición de motivos- "se considera la suscripción de los convenios una manifestación de la autonomía de la voluntad de las cooperativas en el ámbito privado, dentro de la estrategia empresarial, que afecta únicamente a las empresas y a los socios que los suscriben". No obstante, los convenios intercooperativos han de ser publicitados en la web de la cooperativa, cuando dispongan de ella, o en el tablón de anuncios de la cooperativa, aunque pueden arbitrar otras fórmulas de publicidad ${ }^{18}$.

- Decreto Legislativo 2/2015, de 15 de mayo, del Consell, por el que aprueba el texto refundido de la Ley de Cooperativas de la Comunitat Valenciana. Artículo 102.3 $3^{19}$.

Decreto Legislativo 2/2014, de 29 de agosto, del Gobierno de Aragón, por el que se aprueba el texto refundido de la Ley de Cooperativas de Aragón. Artículo $91^{20}$. Su artículo 5, expresamente declara que no se considerarán operaciones con terceros las realizadas en virtud de esos acuerdos intercooperativos ${ }^{21}$.

18 Artículo 141. Convenios intercooperativos.

1. Las cooperativas pueden suscribir con otras cooperativas convenios o acuerdos intercooperativos para el cumplimiento de sus objetos sociales. En virtud de dichos convenios o acuerdos, la cooperativa y sus socios pueden realizar operaciones de suministro, entrega de productos o servicios en las demás cooperativas firmantes del acuerdo o convenio, sin más restricción que las que se puedan derivar de la singularidad o la complejidad de las operaciones cooperativizadas ofrecidas, de los estatutos sociales o de las disposiciones legales. Estas operaciones tienen la misma consideración que las operaciones cooperativizadas con los socios, salvo las operaciones con las secciones de crédito.

2. Las cooperativas que dispongan de sitio web corporativo, en los términos que establece la presente ley, deben hacer públicos los convenios y acuerdos intercooperativos que suscriban con otras cooperativas. Las que no dispongan de sitio web corporativo deben hacer públicos los convenios en el tablón de anuncios de su domicilio social, sin perjuicio de que puedan arbitrar otras fórmulas de publicidad que consideren adecuadas para informar a los socios.

19 Artículo 102. Consorcios y otras uniones. [...]

3. Las cooperativas podrán suscribir con otras acuerdos intercooperativos en orden al cumplimiento de sus objetos sociales. En virtud de los mismos, tanto la cooperativa como sus socios y socias podrán realizar operaciones de suministro, entregas de productos o servicios en las demás cooperativas firmantes del acuerdo, teniendo tales hechos la misma consideración que las operaciones cooperativizadas con los propios socios y socias.

20 Artículo 91. Consorcios, grupos cooperativos, asociaciones y acuerdos intercooperativos.

Para la mejor realización de fines concretos y determinados, de manera temporal o duradera, las cooperativas podrán constituir sociedades y asociaciones, grupos cooperativos y consorcios, suscribir con otras acuerdos intercooperativos, asociarse con otras personas, naturales o jurídicas, y poseer participaciones en ellas.

En virtud de los acuerdos intercooperativos que puedan suscribirse, la cooperativa y sus socios podrán realizar operaciones de suministro, entregas de productos o servicios a la otra cooperativa firmante del acuerdo, teniendo tales hechos la misma consideración que las operaciones cooperativizadas efectuadas con los propios socios.

$21 \quad$ Artículo 5. Operaciones con terceros. 
- $\quad$ Ley 6/2013, de 6 de noviembre, de Cooperativas de Cantabria. Artículo $133.2^{22}$.

- Ley 14/2011, de 23 de diciembre, de Sociedades Cooperativas Andaluzas. Artículo $110.3^{23}$.

- $\quad$ Ley 4/2010, de 29 de junio, de Cooperativas. Comunidad Autónoma del Principado de Asturias. Artículo 136.324.

- $\quad$ Ley 11/2010, de 4 de noviembre, de Cooperativas de Castilla-La Mancha. Artículo $157.2^{25}$.

- Ley Foral 14/2006, de 11 de diciembre, de Cooperativas de Navarra. Artículo $81.6^{26}$, con obligatoriedad de su inscripción en el Registro, conforme a su art. $17.2 \mathrm{i}$ ).

- Ley 8/2006, de 16 de noviembre, de Sociedades Cooperativas, de la Región de Murcia. Artículo 135.2 y $3^{27}$.

Las sociedades cooperativas podrán realizar actividades y servicios cooperativizados con terceros no socios cuando éstos tengan carácter preparatorio, accesorio, complementario, subordinado o instrumental, en los términos que establezcan sus estatutos y con las condiciones y limitaciones que fija la presente ley o sus normas de desarrollo, siempre que tales actividades o servicios tengan como finalidad el desarrollo del objeto social y posibiliten el cumplimiento de los fines de la cooperativa. No se considerarán operaciones con terceros las resultantes de los acuerdos intercooperativos regulados en el artículo 91 de esta ley.

22 Artículo 133. Concepto y caracteres. [...]

2. Las cooperativas podrán suscribir acuerdos intercooperativos en orden al cumplimiento de sus objetos sociales. En virtud de los mismos, la cooperativa y sus socios podrán realizar operaciones de suministro, entregas de productos o servicios en la otra cooperativa firmante del acuerdo, teniendo tales hechos la misma consideración que las operaciones cooperativizadas con los propios socios.

Los resultados obtenidos de estas operaciones tendrán el carácter y destino de resultados cooperativos.

23 Artículo 110. Otras formas de vinculación. [...]

3. Las sociedades cooperativas podrán suscribir acuerdos intercooperativos orientados al cumplimiento de sus objetos sociales. Con arreglo a los mismos, tanto la cooperativa como sus socios y socias podrán realizar operaciones de suministro, entregas de productos o servicios con las demás cooperativas firmantes del acuerdo, teniendo dicha actividad la consideración de operaciones cooperativizadas con las propias personas socias.

${ }^{24}$ Artículo 136. Otras formas de colaboración económica. [...]

3. Las cooperativas podrán suscribir con otras acuerdos intercooperativos en orden al cumplimiento de sus objetos sociales. En virtud de los mismos, la cooperativa y sus socios podrán realizar operaciones de suministro, entregas de productos o servicios en la otra cooperativa firmante del acuerdo, teniendo tales hechos la misma consideración que las operaciones cooperativizadas con los propios socios.

25 Artículo 157. Otras modalidades de colaboración económica.[...]

2. Las cooperativas podrán suscribir con otras acuerdos intercooperativos en orden al cumplimiento de sus objetos sociales. En virtud de los mismos, la cooperativa y sus socios podrán realizar operaciones de suministro, entregas de productos o servicios en la otra cooperativa firmante del acuerdo, teniendo tales hechos la misma consideración que las operaciones cooperativizadas con los propios socios.

Los resultados obtenidos de estas operaciones tendrán el carácter y destino de resultados cooperativos.

26 Artículo 81. Cooperativas de segundo y ulterior grado. Acuerdos intercooperativos. [... ]

6. No obstante lo dispuesto en los anteriores apartados, las cooperativas podrán suscribir con otras los correspondientes acuerdos intercooperativos en orden al cumplimiento de sus objetos sociales.

En virtud de los mismos, las cooperativas y sus socios podrán realizar operaciones de suministro, entregas de productos o servicios en la otra cooperativa firmante del acuerdo, efectuando las facturas y liquidaciones a la otra cooperativa o directamente a sus socios, teniendo tales hechos la misma consideración que las operaciones cooperativizadas con los socios propios y, en consecuencia, el derecho a los mismos beneficios cooperativos y retornos.

Igualmente podrá requerirse a los socios de la cooperativa con la que han establecido el acuerdo, aportaciones o fondos requeridos para acometer las inversiones necesarias. Estas aportaciones podrán ser realizadas por la cooperativa o bien directamente por los socios de la misma.

27 Artículo 135. Concepto y caracteres.[...]

2. Las sociedades cooperativas podrán suscribir con otras acuerdos intercooperativos en orden al cumplimiento de sus objetos sociales. En virtud de los mismos, las sociedades cooperativas y sus socios 
Situación especial la presenta las sociedades cooperativas especiales de Extremadura, a las que remite el artículo 69 de la Ley 2/1998, de 26 de marzo, de Sociedades Cooperativas de Extremadura, y que están reguladas en la Ley 8/2006, de 23 diciembre, de Sociedades Cooperativas Especiales de Extremadura, cuyo artículo 16 contempla las fórmulas de cooperación o colaboración empresarial ${ }^{28}$.

Ley $1 / 2003$, de 20 de marzo, de Cooperativas de las Illes Balears. Artículo $143.2^{29}$. Estableciéndose expresamente que el resultado de esas operaciones se tratará como Excedente cooperativo, conforme al artículo $80.1^{30}$.

- $\quad$ Ley 4/2002, de 11 de abril, de Cooperativas de la Comunidad de Castilla y León. Artículo $128^{31}$. El destino al fondo de Reserva Obligatorio de los resultados de estas operaciones se reitera en el Artículo $71^{32}$.

podrán realizar operaciones de suministro, entregas de productos o servicios en la otra sociedad cooperativa firmante del acuerdo, teniendo tales hechos la misma consideración que las operaciones cooperativizadas con los propios socios

3. Los resultados de estas operaciones se imputarán en un cincuenta por ciento al Fondo de Reserva Obligatorio de la sociedad cooperativa.

28 Artículo 16. Cooperación y colaboración empresarial.

1. La sociedad cooperativa especial podrá constituirse para regular entre varias sociedades, asociaciones, fundaciones, corporaciones o personas físicas actividades de cooperación y colaboración económica, siempre que mediante ella se satisfagan necesidades económicas de sus socios.

Los fines de la cooperación o colaboración empresarial de estas cooperativas especiales podrán ser:

a) El establecimiento de canales de aprovisionamiento, producción o comercialización comunes.

b) La implantación de procedimientos y de compromisos mínimos de calidad en la producción y en los servicios, y de utilización de marcas comunes.

c) La realización de prácticas de responsabilidad social corporativa y la aplicación de medidas de prevención de riesgos laborales de conformidad con lo dispuesto en la normativa específica sobre esta materia.

d) El establecimiento de servicios comunes de asesoramiento comercial, técnico, tributario, económico, jurídico, laboral, o de cualquier otra naturaleza.

e) El establecimiento de relaciones asociativas o de colaboración empresarial entre las sociedades agrupadas.

2. Los estatutos de la sociedad cooperativa especial recogerán la actividad cooperativizada en que se concreten los compromisos generales asumidos por el grupo.

3. La responsabilidad derivada de las operaciones que realicen directamente con terceros contratantes las personas jurídicas o físicas agrupadas no alcanzará a la sociedad cooperativa especial, que responderá exclusivamente por sus actuaciones.

29 Artículo 143. Otras formas de colaboración económica y social.[... ]

2. Las cooperativas podrán suscribir con otras acuerdos intercooperativos para cumplir sus objetivos sociales. En virtud de éstos, la cooperativa y sus socios podrán realizar operaciones de suministro, entregas de productos o servicios en la otra cooperativa firmante del acuerdo. Estos hechos tienen la misma consideración que las operaciones cooperativizadas con los propios socios. Los resultados de estas operaciones se imputarán de acuerdo con lo que dispone el artículo 80.1 de esta ley.

30 Artículo 80. Aplicación de los excedentes.

1. El resultado económico procedente de las operaciones con los socios después de haber deducido las pérdidas de cualquier naturaleza de ejercicios anteriores y antes de considerar el impuesto de sociedades, constituye el excedente cooperativo y se destinará, al menos, el veinte por ciento al fondo de reserva obligatorio, el cinco por ciento al fondo de educación y promoción y el diez por ciento, si existe, al fondo de reserva para retorno de aportaciones.

31 Artículo 128. Acuerdos intercooperativos.

Las cooperativas podrán suscribir entre sí acuerdos intercooperativos en orden al cumplimiento de sus objetivos sociales. En virtud de los mismos, la cooperativa y sus socios podrán realizar operaciones de suministro, entregas de productos o servicios con la cooperativa firmante del acuerdo, teniendo tales hechos la misma consideración que las operaciones cooperativizadas con los propios socios.

Los resultados de estas operaciones se imputarán en su totalidad al Fondo de Reserva Obligatorio de la cooperativa.

32 Artículo 71. Fondo de Reserva Obligatorio. 

c) $)^{33}$.

Ley 4/2001, de 2 de julio, de Cooperativas de La Rioja. Artículo 131.1

Ley 4/1993, de 24 de junio, de Cooperativas de Euskadi. Artículo 134 bis $^{34}$, añadido por el artículo 19 de la Ley 1/2000, de 29 de junio.

Ley 4/1999, de 30 de marzo, de Cooperativas de la Comunidad de Madrid. Artículo 129.1 c), bajo lo que denomina "Conciertos intercooperativos" 35 .

- Ley 5/1998, de 18 de diciembre, de Cooperativas de Galicia. Artículo 111.5 , si bien, únicamente se contemplan para las cooperativas agrarias ${ }^{36}$.

Con todos estos datos, podríamos decir que el acuerdo intercooperativo es un contrato por virtud del cual una cooperativa se compromete a suministrar a otra (o a sus socios) bienes y servicios, actuación que es considerada como operación cooperativizada con socios y no con terceros (Alfonso, 2000: 299; Sánchez, 2015). Los aspectos principales de su regulación los vemos en el apartado siguiente.

El Fondo de Reserva Obligatorio, destinado a la consolidación, desarrollo y garantía de la cooperativa, es irrepartible entre los socios y al mismo se destinarán necesariamente:[...]

e) Los resultados de las operaciones derivadas de los acuerdos intercooperativos de acuerdo con el artículo 128 de esta Ley.

33 Artículo 131. Otras formas de colaboración económica.

1. Las sociedades reguladas en la presente Ley podrán contraer otros vínculos intercooperativos bajo cualquiera de las modalidades siguientes:[...]

c) Acuerdos intercooperativos en orden al cumplimiento de sus objetos sociales.

En virtud de los mismos, la cooperativa y sus socios podrán realizar operaciones de suministro, entrega de productos o servicios en la otra cooperativa firmante del acuerdo, teniendo tales hechos la misma consideración que las operaciones cooperativizadas con los propios socios. Los resultados de estas operaciones se imputarán en su totalidad al fondo de reserva obligatorio de la cooperativa.

34 Artículo 134 bis.

Las cooperativas podrán suscribir con otras acuerdos intercooperativos en orden al cumplimiento de sus objetos sociales. En virtud de los mismos, la cooperativa y sus socios podrán realizar operaciones de suministro, entregas de productos o servicios en las otras cooperativas firmantes del acuerdo, teniendo tales hechos la misma consideración que las operaciones cooperativizadas con los propios socios.

35 Artículo 129. Modalidades especiales de intercooperación.

1. Las sociedades reguladas en la presente Ley podrán contraer otros vínculos intercooperativos bajo cualquiera de las modalidades siguientes:[...]

b) Conciertos intercooperativos para facilitar, garantizar o desarrollar los respectivos objetos sociales. En virtud de estos conciertos, una cooperativa y sus socios podrán recibir o realizar operaciones de suministro o entregas de productos, bienes o servicios en las otras cooperativas firmantes del acuerdo. Tales operaciones tendrán, a todos los efectos, la misma consideración que la actividad cooperativizada con los propios socios.

36 Artículo 111. [...]

5. Las cooperativas agrarias podrán celebrar con otras de la misma clase los acuerdos intercooperativos que correspondiesen, para el cumplimiento de sus objetos sociales. En virtud de estos acuerdos, la cooperativa y sus personas socias podrán realizar operaciones de suministro o entrega de productos o servicios en la otra cooperativa; tales hechos tendrán la misma consideración que las operaciones cooperativizadas desarrolladas con las propias personas socias y no como terceras personas.

6. Las operaciones que realicen las cooperativas agrarias y las de segundo grado que las agrupen con productos o materias, incluso suministrados por terceras personas, se considerarán, a todos los efectos, actividades cooperativas internas con el carácter de operaciones de transformación primaria, siempre que se destinasen únicamente a las explotaciones de sus personas socias. 


\section{Regulación de los acuerdos de intercooperación (acuerdos intercooperativos): aspectos principales de su régimen jurídico}

Si en el análisis de los acuerdos intercooperativos tomamos como referencia la Ley estatal, en términos generales, podremos concluir que, por virtud de acuerdo o convenio, una cooperativa y sus socios podrán realizar operaciones de suministro, entregas de productos o servicios en otra cooperativa firmante del acuerdo. La previsión legal, en este aspecto -se ha dicho- no añade nada a la capacidad de autorregulación contractual de los derechos y obligaciones que corresponde a los particulares. En la cooperativa, como sujeto privado, la autonomía de voluntad y la capacidad de autorregulación de sus derechos y obligaciones justificarían por sí mismas la legitimidad de los acuerdos, si bien -se ha dicho también- "no está demás su reconocimiento con carácter más o menos general" (Romero, 2001: 571).

Sin embargo, con todas las limitaciones que el artículo 79.3 presenta y que críticamente Paz Canalejo puso en evidencia, también supone indudables aciertos que el mismo autor se encargó de relacionar: tributo al principio de intercooperación; amplía la capacidad operacional de las cooperativas para actuar económicamente con quienes no son sus socios sin infringir la legalidad; abre un nuevo cauce a la colaboración económica entre cooperativas y sus socios; y tiene un valor pedagógico al recordar a las entidades de cooperación esta vía de acción entre ellas (Paz, 2004: 157-158).

\subsection{El reconocimiento del carácter cooperativo de las operaciones intercooperativas: funciones y consecuencias}

El hecho fundamental del reconocimiento legal del acuerdo intercooperativo, va a desempeñas así, al menos, dos funciones (Aizega y Valiñani, 2003):

1. Reconocer el carácter cooperativo de las operaciones que resulten de esos acuerdos; con lo que la actuación es considerada como operación cooperativizada con los socios y no con terceros. Los resultados, por tanto, son de carácter cooperativo. No obstante en la Ley estatal y en algunas leyes autonómicas (expresamente en las de Castilla y León, Murcia y La Rioja) los resultados de esas operaciones se imputarán en su totalidad al fondo de reserva obligatorio de la cooperativa, con lo que el destino de esos resultados viene a ser el mismo que si fueran resultados extracooperativos, por lo que un importante sector de la literatura científica propuso, desde hace tiempo, su revisión (Alfonso, 2006:768; Paniagua, 2005: 330; Paz, 2004: 160-163 y 207; Aizega y Valiñani, 2003: 31). En efecto, la imputación en su totalidad al fondo de reserva obligatorio, vendría a contradecir la afirmación que se realiza en el párrafo previo del mismo artículo 79.3 de la Ley de cooperativas cuando dispone -como se hace también en muchas leyes autonómicas- que las operaciones de suministro, entrega de productos o servicios en otra cooperativa tienen la misma consideración que las operaciones cooperativizadas con los propios socios. Es decir, mientras en la determinación del resultado del ejercicio tales operaciones han de conceptuarse como cooperativizadas con socios, su aplicación escapa del régimen previsto para aquellas, sirviendo íntegramente para dotar el fondo 
de reserva obligatorio. Por todo ello, algún autor ha propuesto, pese a la insistencia de la Ley sobre el hecho de que los resultados de esas relaciones se destinen en su totalidad al fondo de reserva obligatorio, una interpretación correctora del precepto, apoyada en una exégesis sistemática, teleológica y lógica del régimen de los distintos tipos de resultados que viene a establecer la Ley, y que permite concluir -se dice- que los resultados de la prestación de los servicios cooperativos a no socios en el marco de esos acuerdos intercooperativos deben quedar sujetos, como mucho, al régimen de los resultados extracooperativos conforme al artículo 58.2 de la Ley. Incluso se defiende su calificación como resultados cooperativos (Paniagua, 2005: 330). Así las cosas, y a la luz de estos razonamientos, entendemos que lo pertinente sería que esas legislaciones que no terminan reconociendo, a todos los efectos, el carácter cooperativo de los resultados de esas operaciones, se replantearan la situación y, con la previsión legal oportuna (también fiscal), dieran la seguridad necesaria en el tratamiento de esos resultados.

2. La segunda función que cumple ese reconocimiento legal es el permitir que la participación de los socios en la actividad cooperativizada pueda hacerse efectiva en otras cooperativas con las que se establezca la relación mediante el correspondiente acuerdo intercooperativo. La previsión legal, pues, puede tener una trascendencia práctica de indudable alcance, no solo tributario sino societario, en cuanto las operaciones no estarían sujetas a los límites legales a esa actividad extrovertida (Paz, 2004), con las consecuencias que puede tener, por ejemplo, para los socios trabajadores o de trabajo, quienes podrán desarrollar su prestación de trabajo bien en la propia cooperativa, de la cual son socios, o en otra cooperativa con la que se haya suscrito un acuerdo de intercooperación ${ }^{37}$. Al margen de estas funciones, no puede olvidarse que el reconocimiento legislativo del acuerdo intercooperativo, aun con todas las limitaciones que padece, no deja de ser una manifestación del principio de intercooperación, y tiene, además, un valor pedagógico indudable al recordar a las entidades y a sus socios esta vía de acción entre las cooperativas.

\subsection{Objeto y ámbito de los acuerdos intercooperativos}

El objeto sobre el que puede versar la colaboración puede consistir-como se viene a decir en las leyes- en el suministro y/o entregas de productos y/o servicios ${ }^{38}$. Por lo demás, conforme está establecido por las legislaciones, puede desprenderse que el acuerdo puede dar lugar a operaciones de los socios de una cooperativa,

37 Incluso se ha apuntado que la falta de previsión legal haría difícil la legitimación de un acuerdo de tales características; porque, aunque las cooperativas pueden entablar entre sí cualquier tipo de relación que tengan por conveniente, sin embargo, a través de esas relaciones o vinculaciones, no se pueden alterar las normas imperativas que rigen las operaciones con socios y terceros (Alfonso, 2006).

38 Aunque algún prestigioso autor $(\mathrm{Paz}, 2004)$ ha señalado la conveniencia de establecer algunos límites a los actos intercooperativos a fin de no desvirtuar el objeto y finalidad de cada cooperativa concertada, en nuestra opinión, no solo no es necesario, sino que sería contraproducente, pudiendo dar al traste con la funcionalidad de los acuerdos intercooperativos. Su legitimidad y control, como en otro momento hemos apuntado, queda bajo la salvaguarda de los principios y valores cooperativos, que han de guiar la actuación de la cooperativa y de los socios. 
concertada con otra, en el seno de ésta, como a operaciones entre y para las cooperativas. La colaboración puede ser unilateral o recíproca. En el acuerdo pueden intervenir dos o más cooperativas, y las cooperativas partícipes del acuerdo pueden pertenecer a cualquier clase o nivel de integración.

Los suministros o entregas se pueden realizar, pues, tanto por la cooperativa firmante del acuerdo como por sus socios y, de la misma manera, el receptor de los mismos puede ser tanto la cooperativa como sus socios; sin que adquieran, en ningún caso, la consideración de terceros. Todo ello porque habrá que considerar las operaciones que deriven del acuerdo intercooperativo como actividad cooperativizada y no como actos externos e instrumentales de la cooperativa.

La utilidad práctica de estos acuerdos intercooperativos parece, pues, clara. Así, cuando exista un acuerdo de esta naturaleza, la actividad cooperativizada se podrá realizar por la cooperativa no sólo con sus propios socios, sino también con la cooperativa firmarte del acuerdo y con los socios de ésta; y, por su parte, los socios de la cooperativa suministradora podrán realizar la actividad cooperativizada no sólo con ella, sino también con la cooperativa receptora y, en su caso, sus socios.

Este tipo de acuerdos, en definitiva, permite ampliar la capacidad operacional de la cooperativa para actuar económicamente con quienes no son sus socios sin infringir la legalidad ${ }^{39}$, aunque esos socios lo han de ser de otra cooperativa, pues lo que no parece válido es que este tipo de acuerdos pueda producir todos sus efectos (cooperativos o fiscales) cuando alguno de los firmantes sea una empresa o entidad no cooperativa.

En un régimen razonable de acuerdos intercooperativos, parece que éstos sólo puedan ser concertados por sociedades cooperativas. No obstante, en nuestra opinión, el legislador cooperativo quizá debiera valorar la pertinencia de admitir el mismo tratamiento para los acuerdos de las cooperativas con entidades que alcancen la consideración de economía social. Teniéndose en cuenta para ello la caracterización de esas entidades que se recoge en la Ley de Economía Social, de 29 de marzo de 2011.

Por lo demás, a falta de mayores previsiones legales en la determinación del régimen jurídico de los acuerdos intercooperativos, será la voluntad común de las cooperativas implicadas la que establezca el contenido del acuerdo: vigencia del acuerdo; ámbito del mismo; consecuencias de incumplimiento; contraprestaciones etc. Todo ello, entendemos, dentro del respeto a la ley -con el reconocimiento de los principios cooperativos- y de las normas estatutarias de cada cooperativa. Como se vino a decir (Duque, 2000: 68), no se discute el reconocimiento a la libertad contractual, tan necesaria para lograr una adaptación a las circunstancias cambiantes de la economía, siempre que se haga con el respeto a principios que se encuentran por encima de los intereses y voluntades particulares, y en la finalidad de promover, coordinar y desarrollar fines económicos comunes de los socios, y de reforzar e integrar la actividad económica de los mismos; o como se dice en el

39 En la práctica, no son infrecuentes estos modelos de cooperación; contamos, además, con sugerentes ejemplos (Sánchez, 2011) cuya promoción y fomento se justifica y ampara por el mismo principio de la intercooperación. Uno de los últimos ejemplos nos lo dan las cooperativas sevillanas Lincoman Servicio de Limpieza y el centro educativo Aljarafe, que funciona como cooperativa. https://www.faecta.coop/index.php?id=14\&tx_ttnews $\% 5 \mathrm{Btt} \_$news $\% 5 \mathrm{D}=5593 \& \mathrm{cHash}=175 \mathrm{~d} 07 \mathrm{a} 4 \mathrm{ca} 133 \mathrm{~b} 38 \mathrm{e} 9$ 88a2b63f246d01. 
artículo, aunque sea sin la precisión deseable, en orden al cumplimiento de sus objetos (alguna ley autonómica dice objetivos) sociales. Por ello, no parece que estos casos (ni cualquiera de esas «otras modalidades de colaboración económica») puedan ser utilizadas para dejar sin contenido a los principios cooperativos, que inspiran la estructura y el funcionamiento de las cooperativas, ni para vulnerar la legislación cooperativa imperativa. En caso contrario, entendemos, dichos acuerdos intercooperativos adolecerían de un vicio de invalidez y, como tal, podrían ser rebatidos.

\section{Consideraciones finales}

Hemos constatado que la dimensión de las empresas sigue siendo una de las principales estrategias a la hora de abordar muchos de los retos a los que se enfrenta el sector cooperativo. La atomización y reducida dimensión empresarial, que particularmente ofrecen las cooperativas en España, se presenta como un límite de su capacidad competitiva. Alcanzar una dimensión suficiente ya no es solo una tendencia o necesidad de los planes de negocio sino que, además, en algún sector, como en el del cooperativismo agroalimentario, se ha convertido en una política pública fomentada y apoyada económicamente, como se desprende de la ya citada Ley 13/2013, de 2 de agosto.

La legislación cooperativa española alude a diversos instrumentos o modalidades de integración o colaboración, que no siempre han tenido los mejores resultados. Más recientemente, frente a los instrumentos de integración más rígidos o intensos, como puede ser la fusión, la cooperativa de segundo grado u otros tipos de agrupaciones cooperativas, el sector cooperativista también reclama fórmulas de integración o colaboración más flexibles para redimensionar las cooperativas. En este aspecto, los acuerdos de intercooperación, en sus distintas modalidades, nos parece que pueden presentarse, mutatis mutandis, como un instrumento idóneo para la integración o colaboración y para la intercooperación, siempre con en el respeto de los valores y principios que sirven de identidad y guía al cooperativismo.

En la búsqueda de instrumentos jurídicos adecuados que den respuestas adecuadas al cooperativismo, no podemos desconocer la complejidad que, en nuestro país, afecta de lleno a su regulación y que hace que siga siendo recomendable - aun con todas las dificultades que supone- una Ley armonizadora, al amparo del artículo 150.3 de la Constitución Española (Vargas et al., 2017). No son infundados los temores de quienes ven en la proliferación de legislación cooperativa en España un obstáculo a la eficiencia económica del movimiento cooperativo e, incluso, un impedimento o limitación a los procesos de concentración económica entre cooperativas sujetas a distintas leyes; lo que termina generando una atomización de las empresas cooperativas que dificulta su competitividad. Todo ello reclama un firme compromiso de los legisladores, nacional y autonómicos, para la búsqueda, "mediante una legislación adecuada», del fomento de las sociedades cooperativas (art. 129.2 CE), en el marco de unidad de mercado, que también garantiza nuestro texto constitucional (art. $139 \mathrm{CE}$ ).

En particular, por lo que concierne a los acuerdos intercooperativos, se hace apremiante una unificación de su tratamiento jurídico, al menos, en lo que concierte al tratamiento del destino del resultado de esas operaciones al fondo de 
reserva obligatorio de las cooperativas. Tampoco estará demás reconocer la pertinencia de una inscripción registral de dichos acuerdos interpooperativos e, incluso, la posibilidad de su extensión a las entidades que tengan la condición o la calificación de economía social. Una regulación uniforme y coherente, dentro del ámbito de la autonomía de la voluntad y capacidad autorreguladora del cooperativismo, podría hacer de este instrumento un mecanismo idóneo y atractivo para la integración cooperativa y dar una adecuada respuesta a modelos para intercooperar que se demandan en nuestro país.

\section{Referencias bibliográficas}

Aizega Zubillaga, J. M. y Valiñani González, E. (2003) Las cooperativas de segundo grado, grupo cooperativo y otras formas de colaboración, REVESCO. Revista de Estudios Cooperativos, $\mathrm{N}^{\mathrm{o}} 79$, pp. 7-33.

Alfonso Sánchez, R. (2000) La integración cooperativa y sus técnicas de realización: La cooperativa de segundo grado. Valencia: Tirant lo Blanch.

Alfonso Sánchez, R. (2006) Grupos y alianzas de sociedades. Especial referencia al grupo cooperativo y a la cooperativa de segundo grado. En: Pulgar Ezquerra, J. (Dir); Vargas Vasserot, C. (Coord) Cooperativas agrarias y sociedades agrarias de transformación, Madrid: Dykinson.

Alfonso Sánchez, R. (2015) Los principios cooperativos como principios configuradores de la forma social cooperativa. Revista jurídica de Economía Social y Cooperativa, Monográfico Principios y valores cooperativos. № 27, pp. 49-85.

Antelo, A. B. (2012) Integración de cooperativas: Ayudar a crecer, Alimarket, No 267, pp. 7-11.

Arcas Lario, N. (2011) Las cooperativas agrarias en la Unión Europea y España: evolución de su tamaño y poder de negociación, Tierras de Castilla y León: Agricultura, $\mathrm{N}^{\mathrm{o}} 176$, pp. 70-79.

Argudo Périz, J. L. (2007) La multifuncionalidad de las instituciones jurídicas asociativas agrarias en las políticas de desarrollo rural y regional. REVESCO. Revista de Estudios Cooperativos, $\mathrm{N}^{\circ}$ 92, pp. 11-40.

Campos Climent, V. (2011) La crisis de la agricultura y el papel de las cooperativas agrarias, Tierras de Castilla y León: Agricultura, № 185, pp. 28-36

Campos Climent, V. y Chaves Ávila, R., (2012) El papel de las cooperativas en la crisis agraria. Estudio empírico aplicado a la agricultura mediterránea española. Cuadernos de desarrollo rural, $\mathrm{N}^{\circ}$ 9, Vol. 69, pp. 173-194.

Cano Ortega, C. (2015 a) La fusión de cooperativas. Madrid: Marcial Pons.

Cano Ortega, C. (2015 b) Una perspectiva actual del sexto principio cooperativo: Cooperación entre cooperativas. Revista jurídica de Economía Social y Cooperativa, Monográfico Principios y valores cooperativos. N 27, pp. 285-331.

Carnicer Andrés, M ${ }^{\mathrm{a}}$ P. (2017) Nuevos modelos organizativos de las cooperativas agroalimentarias europeas y españolas: resiliencia vs. Desmutualización. Tesis Doctoral. Valencia. Disponible en internet: https://riunet.upv.es/bitstream/handle/10251/86170/Carnicer\%20\%20NUEVOS\%20MODELOS\%20ORGANIZATIVOS\%20DE\%20LAS\%20COOPER ATIVAS\%20AGROALIMENTARIAS\%20EUROPEAS\%20Y\%20ESPA\%C3\%91OL AS....pdf? sequence $=1$. 
Cuenca García, A. (2000) Las cooperativas de segundo grado en la Ley 27/1999, de 16 de julio, de cooperativas, Ciriec-España. Revista Jurídica de Economía Social y Cooperativa, $\mathrm{N}^{\mathrm{o}} 11$, pp. 69-118.

Del Real Sánchez-Flor, J. M. (2013) La dimensión como clave para la mejora de la competitividad. Mediterráneo Económico, No 24, pp. 321-344.

Duque Domínguez, J. F. (2000) Recientes desarrollos del Derecho de los grupos de sociedades en el Derecho español. Boletim da Faculdade de Direito, $\mathrm{N}^{\mathrm{o}} 48$, Universidade de Coimbra, Coimbra, pp. 43-85.

Embid Irujo, J. M. (1998) Problemas actuales de la integración cooperativa. Revista de Derecho Mercantil, No 227, pp. 7-36.

Fayos, T., Calderón, H., Mir, J. (2011) El éxito en la internacionalización de las cooperativas agroalimentarias españolas. Propuesta de un modelo de estudio desde la perspectiva del marketing internacional. Ciriec-España. Revista de Economía Pública, Social y Cooperativa, $\mathrm{N}^{\mathrm{o}}$ 72, pp. 43-72.

Gadea, E., Sacristán, F. y Vargas Vasserot, C. (2009) Régimen jurídico de la sociedad cooperativa del siglo XXI. Realidad actual y propuestas de reforma. Madrid: Dykinson.

García Martínez, G., Meliá Martí, E., Arcas Lario, N. (2014) Tamaño y competitividad de las cooperativas agroalimentarias españolas. Tierras de Castilla y León: Agricultura, $\mathrm{N}^{\mathrm{o}}$ 222, pp. 46-55.

Herrero Suárez, C. (2005) Control de las concentraciones de empresas, en Derecho europeo de la competencia, (Coor. Velasco San Pedro, L.). Valladolid: Lex Nova.

Huerta Arribas, E. y Salas Fumás, V. (2014) Tamaño de las empresas y productividad de la economía española. Un análisis exploratorio, en Mediterráneo económico. Un nuevo modelo económico para España, Myro, R. (coord.), Cajamar/Caja Rural, pp. 167-191.

INSTITUTO PARA EL DERECHO Y LA ORGANIZACIÓN EMPRESARIAL (2003) La legislación de cooperativas y el derecho de la competencia: análisis de la normativa de control de concentraciones respecto a los acuerdos de intercooperación. Fundación EZAI, http://www.ezai.coop/IMG/pdf/informe_d-competencia.pdf.

Juliá, J. F., García, G., Meliá, E. (2012) La globalización y los modelos de crecimiento de los grupos cooperativos. Las cooperativas agroalimentarias en España y la Unión Europea. Revista Vasca de Economía EKONOMIAZ, No 79, pp. 82-113.

Juliá, J. F., Meliá, E., García, G., Gallego, P. L. (2010) Los factores de competitividad de las cooperativas líderes en el sector agroalimentario europeo. Acciones a emprender por las cooperativas agrarias españolas. Colección económica, 14. Almería: Fundación Cajamar.

Meliá Martí, E. y Juliá Igual, J. F. (2008) La intercooperación: Una respuesta a las actuales demandas del cooperativismo agrario. Estudios de Economía Aplicada, № 26-1, pp. 5788.

Monzón Campos, J. L. (2012) Las cooperativas ante la globalización: magnitudes, actividades y tendencias. Revista Vasca de Economía EKONOMIAZ, No 79, pp. 12-29.

Morillas Jarillo, M J. y Feliú Rey, M. I. (2002) Curso de Cooperativas. Madrid: Tecnos, $2^{\mathrm{a}}$ Ed.

Paniagua Zurera, M. (2005) Las sociedades cooperativas. Las sociedades mutuas de seguros y las mutualidades de previsión social, en Tratado de Derecho Mercantil, La sociedad cooperativa. Las sociedades mutuas y las entidades mutuales. Las sociedades laborales. La sociedad de garantía recíproca, (Coor. Jiménez Sánchez, G.) Vol. I. Madrid: Marcial Pons.

Paz Canalejo, N. (2004) Los acuerdos intercooperativos en el Derecho vigente (estatal y autonómico). Revista Jurídica del Notariado, No 52, pp. 137-209. 
Romero Candau, P. A. (2001) Comentario en AA.VV. Cooperativas. Comentarios a la Ley 27/1999, de 16 de julio, T. I, Consejo General del Notariado, Madrid.

Sánchez Pachón, L. A. (2007) Cuestiones generales sobre la Ley de Cooperativas de Castilla y León, Revista Jurídica de Castilla y León, No 13 pp. 253-300.

Sánchez Pachón, L. A. (2009) La delimitación de las entidades y organizaciones de economía social en la próxima ley reguladora del sector", Ciriec-España. Revista de Economía Pública, Social y Cooperativa, № 66, pp. 61-84.

Sánchez Pachón, L. A. (2010) El reconocimiento de la economía social y de sus agentes en el Proyecto de Ley de Economía Social, en Noticias de la Economía Pública Social y Cooperativa, $\mathrm{N}^{\mathrm{0}}$ 54, pp. 53-58.

Sánchez Pachón, L. A. (2011) Los acuerdos intercooperativos. Un instrumento jurídico para la colaboración en momentos de crisis económica, Ciriec-España. Revista Jurídica de Economía Social y Cooperativa, No 22, pp. 121-149.

Sánchez Pachón, L. A. (2015) Modalidades de integración y colaboración de las cooperativas en Castilla y León y perspectivas de desarrollo. Revista jurídica de Castilla y León, № 36, pp.123-164.

Vañó Vañó, Ma J. (2011) Intercooparación a través de cooperativas de servicios empresariales y de segundo grado. III Congreso Internacional de Investigación en economía social de CIRIEC, pp. 1-11.

Vargas Vasserot, C. (2010) La integración y diferenciación cooperativa: de las secciones a los grupos de sociedades. Boletín de la Asociación Internacional de Derecho Cooperativo $\mathrm{N}^{\circ} 44$, pp. 159-176.

Vargas Vasserot, C., Gadea Soler, E. y Sacristán Bergia, F. (2017) Derecho de las sociedades cooperativas. Régimen económico, integración, modificaciones estructurales y disolución. La Ley. Madrid: Wolters Kluwer. 